\title{
Injury Prevention in The Sport of Surfing: An Update
}

\author{
A. Nathanson \\ Department of Emergency Medicine, Alpert Medical School of Brown University, Providence, USA
}

\section{CORRESPONDING AUTHOR:}

Andrew Nathanson

Department of Emergency Medicine

593 Eddy Street, Claverick 2

Providence, RI 02903, USA

E-mail: ANathanson@lifespan.org

DOI:

10.32098/mltj.02.2020.03

LEVEL OF EVIDENCE: 4

\begin{abstract}
SUMMARY
Background. The aim of this study is to review the literature on surfing injuries, with a focus on severe injuries, big-wave surfing and injury prevention.

Methods. A literature search of the MEDLINE database from 1980 to present via Pubmed and OVID was done using the terms surfing, bodyboarding, bodysurfing, injury and injuries. Relevant books and websites were also referenced regarding recommendations for injury prevention. A total of 46 articles were retrieved, from which 37 were selected.

Results. The injury rate in surfing has been found to be 1.8 significant injuries per 1,000 hours and 3.5 per 1,000 days for recreational surfers and 4.0 per 1,000 days and 6.6 per 1,000 hours for competitive surfers. Lacerations are the most common type of injury accounting for $37-46 \%$ of all injuries followed by sprains/strain, contusions, fractures and dislocations. Impacts with surfboards (45-66\%) and the sea floor are the most common mechanisms of injury. The most catastrophic injuries include drowning and injuries to the head and neck, often caused by impact with the sea floor. Conclusions. Surfing is relatively safe compared to other extreme sports. Injury rates can likely be mitigated by the modification of surfboard design and the use of protective personal equipment.
\end{abstract}

\section{KEY WORDS}

Surfing, bodyboarding, injury, injury prevention

\section{BACKGROUND}

Surfing, first practiced by Polynesians over 800 years ago, is arguably the oldest extreme sport; it is also among the most popular (1). Since being introduced to the United States and Australia by the Hawaiian Olympic swimming champion, Duke Kahanamoku, in the early $20^{\text {th }}$ century, participation in the sport has grown rapidly (1). A professional surfing tour was first established in 1968 and by a 2013 estimate, there were between 26 and 35 million active surfers worldwide $(2,3)$. In addition, the sport is having its Olympic debut in 2020.

Waves can be ridden in a variety of ways: body surfing (no board); bodyboarding (prone on small board); surfing (standing on surfboard); stand-up paddle boarding also known as SUP (standing on surfboard, propelled by paddle); tow-in surfing (towed onto a wave via jet-ski, riding a surfboard); and surf foiling (standing on board equipped with underwater foil).
The types of waves ridden vary in size, shape, bottom composition and water temperature. Since the 1950's, "big wave" surfers have sought to ride ever bigger waves. By the 1960 's, surfers were successfully paddling into waves as high as 7 -meters. With the assistance of jet-skis, tow-in surfers began tackling 15-meter waves in the mid-1990's and waves approaching 25 meters by the year 2000 . The last decade has seen the improvement of man-made wave pools, enabling high-performance wave-riding at inland locations.

Most of the literature regarding wave-riding injuries consists of survey-based studies, hospital-based chart reviews, or case series focused exclusively on surfing, though some include other wave-riding disciplines. The aim of this paper is to review the hazards associated with wave riding with an emphasis on severe surfing injuries and big-wave surfing (waves $>7$ meters). Injury prevention strategies will be addressed in detail. 


\section{MATERIALS AND METHODS}

The author searched the MEDLINE database from 1980 to present via Pubmed and OVID with the terms surfing, bodyboarding, bodysurfing, injury and injuries. Studies were limited to the English language. While most studies were descriptive and retrospective, some were prospective. Relevant books and websites were also referenced regarding recommendations for injury prevention. A total of 46 articles were retrieved, from which 37 were selected as a result of study size, quality, or focus. Preference was given to hospital-based studies.

\section{RESULTS}

\section{Incidence of injury and risk factors}

In survey-based studies, Lowden found that the rate of "moderate to severe" injuries (resulting in lost days from surfing/work) was 3.5 and 4.0 per 1,000 surfing-days for amateurs and professionals, respectively (4,5). Furness et al. surveyed 1,348 Australian surfers and found a rate of 1.8 "major" injuries (lost days from surfing/work or sought medical care) per 1,000 surfing-hours and that $38 \%$ of respondents suffered a major injury within the past 12 months (6). In a prospective study of 37 surfing contests, Nathanson reported 6.6 "significant" (lost time from surfing or requiring sutures or hospitalization) injuries per 1,000 hours of competition and 5.7 per 1,000 heats. These injury rates were significantly less than those for American College football (33 per $1000 \mathrm{~h}$ ) or soccer (18 per $1000 \mathrm{~h}$ ) in studies using similar methodologies and definitions of injury (7). A post-hoc analysis of that data found a significantly higher injury rate at the 4 contests held at Oahu's Pipeline (32 per 1,000 h), a large tubular wave breaking over a shallow reef. The relative risk of injury in Nathanson's study was increased by 2.4 when surfing in waves greater than head high, and by 2.6 when surfing over a hard (non-sand) sea floor. Another survey-based study found that surfers older than age 40 , and those that were self-rated experts, were almost twice as likely to suffer severe injuries as compared to their younger and less proficient counterparts (8). In a review of 2072 patients presenting to emergency departments across the US, being over 60 years old was associated with a higher risk of admission (9).

\section{Types and mechanisms of injury}

Numerous studies have examined type and anatomic location of surfing-related injuries and a few have assessed mechanism of injury. Impacts with surfboards are reported as the leading cause of acute injury (45-66\%), with the majority of those injuries inflicted by the board's fins, nose, and tail $(7,8,10)$. An internet-based survey reporting 1237 acute injuries found that $55 \%$ were from the surfer's own board, $11 \%$ from another surfer's board, $17 \%$ from the sea floor, $7 \%$ from the force of the wave, and 3\% from marine animals. In one large study, lacerations from surfboard fins accounted for $30 \%$ of all acute surfing injuries (8) (figure 1). The majority of studies have found lacerations to be the most common type of injury $(37 \%-46 \%)$, followed by sprains/strains, contusions, fractures and dislocations (8, $10,11)$. Most commonly injured are the head/face region and lower extremity (table I). Overuse injuries are predominantly to the shoulder, back, and knee $(10,14)$. While minor sprains and strains are common, long bone fractures and dislocations cause a lower proportion of surfing injuries $(5-16 \%)$ than in many land-based sports, but account for a disproportionate number of surfing injuries requiring hospitalization and surgery. In a retrospective study of injuries among professional surfers at a single orthopedic center, the most frequently injured body parts were knee $(28 \%)$, ankle $(22 \%)$, and shoulder (19\%). Lower extremity injuries primarily affected the back leg $(73 \%)$. The most common surgery was repair of rotator cuff tears and superior labrum tears caused by overuse (14).

In big-wave surfing, most injuries are the result of being struck by the powerful cascading lip of a wave and by being

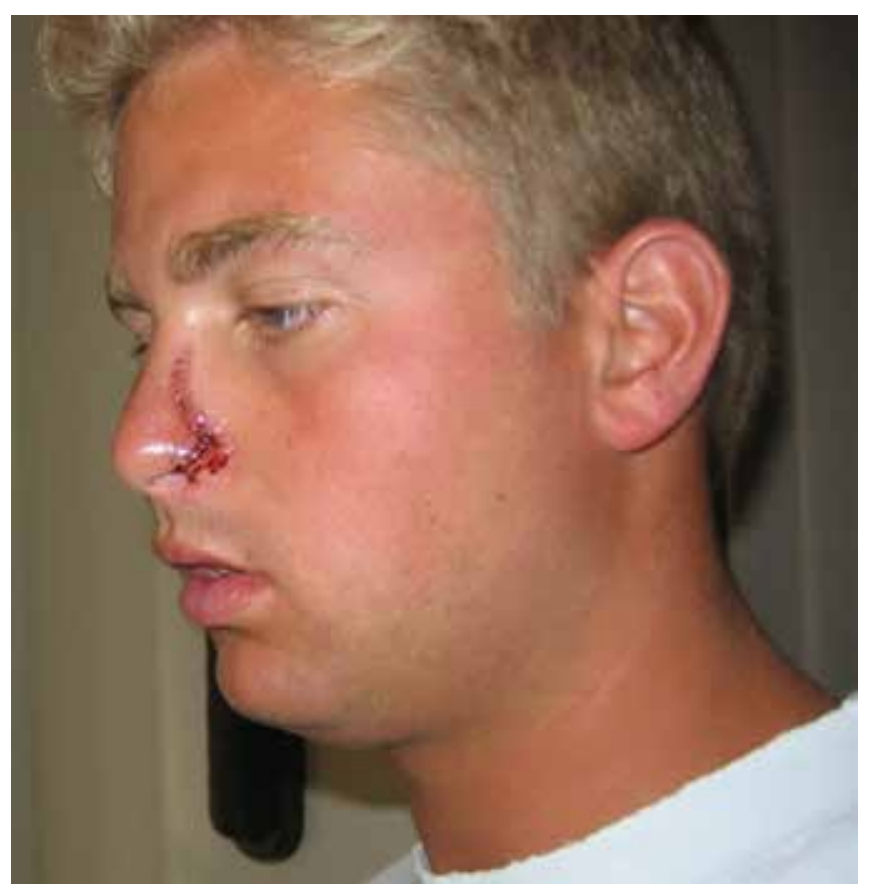

Figure 1. Laceration from fins of surfer's board. Credit: SurfCo Hawaii. 
Table I. Title: Hospital-based studies of waveriding-related injuries.

\begin{tabular}{|c|c|c|c|c|c|}
\hline Study & Chang [12] & Taylor [10] & Hay [11] & Klick [9] & Jubbal [13] \\
\hline Admission Rate & $100 \%$ & Unknown & $10 \%$ & $3.5 \%$ & $71 \% ; 49 \%$ ICU \\
\hline Number of Subjects & 47 (21 bodysurfers) & 267 & 212 & 2072 & 93 (16 bodyboarders, 14 bodysurfers) \\
\hline Average Age & $\sim 27$ & $75 \%<30$ & 27 & 27 & 38 \\
\hline Male Gender & & & & & \\
\hline \multicolumn{6}{|l|}{ Injury Type } \\
\hline Laceration & $13 \%$ & $47 \%$ & $35 \%$ & $41 \%$ & Unknown \\
\hline Sprain/Strain & $13 \%$ & $12 \%$ & $18 \%$ & $14 \%$ & Unknown \\
\hline Contusion & $2 \%$ & $0 \%$ & $12 \%$ & $13 \%$ & Unknown \\
\hline Drowning/Submersion & $2 \%$ & $0 \%$ & $<1 \%$ & $<1 \%$ & Unknown \\
\hline Intrabdominal Injuries & $2 \%$ & $0 \%$ & $<1 \%$ & $<1 \%$ & Unknown \\
\hline Concussion/Intracranial & $17 \%$ & $3 \%$ & $2 \%$ & $7 \%$ & Unknown \\
\hline \multirow[t]{2}{*}{ Other/Unknown } & $4 \%$ & $21 \% a$ & $1 \% 6$ & $8 \% c$ & Unknown \\
\hline & & & & & \\
\hline \multicolumn{6}{|l|}{ Body Region } \\
\hline Lower ext & $19 \%$ & $23 \%$ & $20 \%$ & $26 \%$ & $15 \%$ \\
\hline Intraabdominal & $2 \%$ & $0 \%$ & $16^{*}$ & $1<\%$ & $5 \%$ \\
\hline Other/Unknown & $17 \%$ & $0 \times$ & ox & $3 \%$ & os \\
\hline \multicolumn{6}{|l|}{ a Includes 4 eye injuries } \\
\hline \multicolumn{6}{|c|}{ b Laryzeal fracture, urethral rupture } \\
\hline c Dental Injuries, nerve c & cardial infarction & & & & \\
\hline
\end{tabular}

forcefully driven underwater (15). Because big waves generally break deep water, striking the sea floor is unusual. Injuries occurring during the World Surfing League's "Big-wave tour" include shoulder dislocations, ruptured tympanic membranes, long bone and rib fractures, and lung barotrauma, resulting in hemoptysis and pneumothorax. A "shaken surfer syndrome" has also been described in which a surfer emerges from a severe wipeout mildly disoriented and ataxic without loss of consciousness (15).

Surfers are also at risk of environmental injuries including hypothermia, bony exostosis of the ear, otitis externa, pterygium, sunburn and skin cancers, and bites and stings from marine animals such as jellyfish, and stingrays. ${ }^{8.10,16}$ While rare, shark attacks also present an environmental risk. There are approximately 66 shark bites reported annually worldwide, with a $7 \%$ mortality rate, and $55 \%$ involve "surface recreationists" such as surfers and bodyboarders (17).

\section{Severe and catastrophic injuries}

Catastrophic and fatal injuries are rare but do occur. Among 2072 patients presenting to US emergency departments, only $5 \%$ required admission (9). The most common catastrophic injuries requiring hospitalization are cervical spine fractures, spinal cord injuries, complex lacerations to the face often accompanied by facial fractures, closed head inju- ries, and drownings $(9,13)$. Deep lacerations caused by surfboard fins involving major vessels, viscera, rectum and head are also well described $(18,19)$. Kim et al reported a series of 11 serious eye injuries all caused by the recoil of the surfer's board on its leash, 5 resulting in permanent loss of vision (24). Blunt trauma from surfboards and the sea floor is less common, but has resulted in splenic and liver injuries, rib fractures and pneumothorax $(8,9)$.

An analysis of 93 patients admitted to a Level 1 Trauma center for wave-riding injuries (surfers, bodyboarders, and bodysurfers), found injuries to the spine (51\%), head $(46 \%)$, and face $(23 \%)$ were most common. Fifty percent of patients required intensive care unit stays, and 28 surgical interventions were performed, $71 \%$ of which involved the head or neck (13). Traumatic brain injury occurred in 34\%. Chang, et al analyzed seventy-six cervical spine fracture related to wave-force injuries among body surfers, bodyboarders, skim boarders and surfers in Hawaii and found that $96 \%$ occurred in hollow, plunging-type waves breaking over a steeply sloped sea floor. Thirteen percent of patients suffered permanent quadriplegia and $59 \%$ of patients were discharged with residual neurologic deficits (20). The study concluded that males over 40 with large builds, pre-existing cervical stenosis and degenerative spondylosis, and little surfing experience may be predisposed to spinal cord injury, predominantly from hyperextension. In younger surfers, 
axial loading and hyperflexion from head-first contact with the sea floor was the main mechanism of injury. Bodysurfers and bodyboarders are at higher risk for these injuries because they ride head-first, often in plunging near-shore waves breaking into shallow water $(20,21)$.

In 2004, a series of non-traumatic thoracic spinal cord injuries occurring to young, healthy, novice surfers was first described by Thompson, which he termed "surfer's myelopathy" (22). These uncommon spinal cord infarcts typically involve a first-time surfer who develops sudden onset low back pain, lower extremity paresthesia, followed by lower extremity weakness and urinary retention. Recovery is variable with some patients developing permanent paresis and bladder dysfunction. The pathophysiology is thought to involve ischemic injury to the spinal cord, caused by kinking or vasospasm of the artery of Adamkiewicz, related to prolonged hyperextension of the back (23).

\section{Fatalities}

The fatality rate in surfing is unknown. According to data from the Hawaii Department of Health, among 538 ocean drowning deaths in that state from $2005-14,7 \%$ were surfers or bodyboarders (25) In an epidemiological study of 2072 surfing injuries presenting to emergency departments across the US, there was only 1 fatality (9).

The highest number of fatalities are due to large, powerful, tubular waves which break on to shallow water such as Pipeline, Hawaii (14 deaths since 1960), Teahupo'o, Tahiti (5 deaths) and "The Wedge", California (26). Most of these deaths occur when a surfer goes "over the falls" and hits their head on the sea floor, with resultant loss of consciousness or spinal cord injury. At Jaws (Maui) and Nazare (Portugal), among the most famous big-wave breaks in the world, there have never been any fatalities, and at Maverick's (California) there have been only two (26).

In a review of 95 surfing fatalities occurring from 1982 to 2011 found on the Lexis/Nexis database, drowning was stated to be the cause of death in 63 cases. Factors contributing to these drownings were concussions (11), leash entanglement (4), and seizures (4). Shark attacks were responsible for 12 deaths, lightning strikes for 8 and lacerations from surfboard fins for 2 others (27).

\section{DISCUSSION}

The overall incidence of injury in surfing is lower than that of most extreme sports, and in most conditions, compares favorably to many traditional field sports such as football and rugby. Unlike many other sports where there are collisions with hard surfaces or other athletes, water provides a forgiving surface on which to fall. Most surfing injuries occur when a surfer collides with a surfboard or the sea floor, and those risks can likely be mitigated by modifications in surfboard design and the use of personal protective equipment (see below).

The most dangerous waves appear to be those that break over a steeply inclined sea floor, creating powerful, tubeshaped, plunging waves that begin to crest in deeper water, but whose lips land in shallow water. These waves are highly sought after by surfers seeking exciting "tube" rides under a wave's curl. Expert surfers learn how to avoid injury from the sea floor in these conditions by successfully managing to negotiate the takeoff, and by penetrating through the wave during a wipeout, avoiding going "over the falls" and being thrown forcefully onto the sea floor. However, even experts are seriously injured, and on very rare occasions, killed in these conditions. The majority of these fatalities are due to drowning, often precipitated by head and spine injuries.

Since the beginnings of big-wave surfing in the 1950's, fewer than 15 accomplished big-wave surfers have died surfing, far fewer than most other extreme sports (28). By comparison, during that period, over 300 mountain climbers have died on mount Everest alone (29). There are numerous reasons for the surprisingly low number fatalities. Truly big surf only breaks a few times a year at any given location, limiting exposure time. Because of their intimidating nature, few people choose to ride these waves, and those that do are extremely experienced surfers. Furthermore, due to a number of near-drowning episodes among the sport's elite, a culture of safety has evolved. The vast majority of big-wave surfers now wear flotation devices and most have a jet-ski driver available to pull them out of harm's way (30). Since 2011, the Big Wave Risk Assessment Group in Hawaii and others in Europe have organized courses on big-wave risk assessment, jet-ski rescue skills, breath holding, first-aid, and CPR. While some fear that the use of jet-skis and floatation devices may create a false sense of security among less experienced surfers, the number of fatal accidents does not appear to be increasing despite a larger number of participants (31).

\section{Injury prevention}

\section{Surfboard}

A number of alterations to surfboard design have been proposed to decrease the risk of surfboard-related injuries:

- fins should be designed to break-away with significant impact at their connection point to the surfboard. Fins should have rubberized edges (commercially available) or they should have trailing edges which are at least $2 \mathrm{~mm}$ wide. The tips of fins should be rounded $(4,32)$; 
- noses and tails or boards should be rounded to a "Dolphin Nose" shape with a radius of at least $37 \mathrm{~mm}$ as recommended by the Surfrider Foundation Australia. Expert surfers agree that this would result in no change in board performance. Shock-absorbing materials applied to the boards tail and nose are also likely to mitigate board-related injuries (33);

- surfboard leashes are recommended. Leashes keep the surfboard in close proximity to the surfer and the board serves as a flotation device should the surfer become injured or fatigued. They should be designed to minimize recoil, so the board is less likely to snap back at its rider. Leashes should have a quick-release at the surfer's ankle which can be deployed should the leash snag on the sea floor. In big waves, an extra-thick and longer leash should be used (32);

- beginners should use boards made entirely of shock-absorbing material equipped with flexible fins, as they frequently get hit by their own board.

\section{Personal protective gear}

Head and facial injuries account for a substantial proportion of surfing injuries, and head injuries resulting in loss of consciousness in the water can be fatal (table I). Helmets have been shown to lower the risk of skull fractures and lacerations in other sports and protect against tympanic membrane rupture, however their role in reducing concussions is less clear. Most authorities recommend the use of surf-specific helmets when surfing in large hollow waves over shallow reefs, in strong-offshore winds (boards can become air-borne after a wipeout) when surfing alone, or in very crowded conditions (32). Taylor found that low adoption rates are due to concerns that a helmet may make ducking through oncoming waves more difficult, adversely affect hearing and balance, and may be uncomfortable or unfashionable (34).

Temperature-appropriate wetsuits should be worn, as they not only help to prevent hypothermia, but also provide some buoyancy and protection from UV radiation, abrasions, and jellyfish stings. Surfers are at high risk of developing various forms of skin cancer due to high levels of exposure to UV radiation, and melanoma is likely a leading cause of surfing-related fatalities (35). Avoiding direct sun exposure between $10 \mathrm{am}$ and $2 \mathrm{pm}$, wearing sun-protective clothing, and applying sunscreen are the most effective strategies in reducing the risk of sunburn, melanoma and squamous cell carcinoma (36 Burnett). Zink oxide based, broad-spectrum, $\mathrm{SPF}>30,80$-minute water-resistant sunscreen should be applied to face, lips, and all other uncovered skin and reapplied every 80-120 minutes. For long surfing sessions, a small tube of sunscreen can be tucked under the wetsuit to facilitate re-application. UV-protective clothing is superior to sunscreen, and in tropical conditions, a long-sleeved rash-guard with a hood or hat should be worn to block UV radiation.

\section{Big-wave surfing}

Big-wave surfing (waves $>7 \mathrm{~m}$ ) can be accomplished in relative safety, given the proper experience, physical conditioning, training and equipment. The following recommendations are made based on expert opinion and fatality data. Jet-skis equipped with an affixed floating sled are excellent surf-rescue tools and have significantly improved the safety of big-wave surfing (figure 2). To date, no one has died while tow-in surfing, though there have been a number of non-fatal drownings requiring resuscitation (31). It is essential that jet-ski drivers practice surf-zone pick-up skills with their surfing partners and are trained in first-aid and cardio-pulmonary resuscitation. Water-safety teams at big-wave surfing contests divide a surf break into zones (e.g. outside, impact zone, inside), with 2 skis assigned to each zone. If a driver misses his/her pick-up, a backup is ready. They also use on-shore spotters who can communicate the location of fallen surfers via radio to jet-ski drivers, in order to facilitate rapid pick-up in what is often a dynamic and chaotic environment (15). This strategy serves as good safety model during non-contest days where many surfers have their own jet-ski driver, and some go without. Prior to every big-wave session, an evacuation plan should be in place with a designated ambulance and/or helicopter-accessible evacuation site that can be easily reached from the water.

In big surf, a flotation vest should be worn. Since their implementation, no big-wave surfer has ever died wearing one (28). They help the surfer surface more rapidly in extremely turbulent, highly aerated white-water after a wipeout. They also keep an unconscious victim at the surface where they can be more easily spotted by rescuers. Foam vests provide impact resistance, are not prone to failure and work even if the surfer is unconscious but make diving under oncoming waves more difficult. $\mathrm{CO} 2$ - inflatable vests must be triggered by the surfer, but are less bulky, provide greater buoyancy and when uninflated, allow the surfer to more easily dive under approaching waves.

Breath holding is of vital importance to big-wave surfers, as the risk of drowning is always of concern. On very rare occasions, surfers are held underwater by two consecutive waves before surfacing and may need to hold their breath for as long as 40 seconds - this may be extremely challenging following a period of strenuous paddling. Breath-hold training can significantly improve static and dynamic apnea times, which may be life-saving. Training involves mental and physical relaxation to decrease oxygen demand, as well as learn- 
ing techniques to suppress the urge to breath when experiencing hypercarbia. Anaerobic physical conditioning using high-intensity interval training also aids in breath-holding capacity (37 Fitz-Clark). All in-water apnea training should be done under strict, arms-reach supervision, and hyperventilation prior to a breath-hold should be avoided as shallow water-blackout due to hypoxia can be fatal.

\section{Wipe out techniques}

Like riding waves, wiping out is a skill. Surfers have some control over how they fall and the actions they take can minimize their risk of injury.

Just prior to falling, surfers should take in a deep breath, attempt to fall seaward (behind) of their board, and place arms overhead to protect their head and neck. Once submerged, the surfer should stay calm, and avoid attempts to surface until turbulence subsides, so as not to deplete oxygen reserves. Arms should remain over-head until the surfer has surfaced and located their board. In shallow water, the surfer should land flat to maximize the cushioning effect of the water and avoid hitting the sea floor. Wipeouts while tube-riding are the most hazardous, and the objective is to dive cleanly through wave's base, avoiding the lip and the shallows (32 SS2).

In big waves, surfers should always avoid overexertion, by always being prepared for a long underwater hold-down. If "caught inside" of a large breaking wave, the surfer should make all efforts to avoid getting hit by the wave's powerful lip. For waves about to break, it is best to abandon the board (making sure no one is behind) and attempt to swim through the wave's base (figure 3). For waves which have already broken, it is safest to dive deeply $(3 \mathrm{~m})$ to avoid the most severe turbulence (28 Renneker).

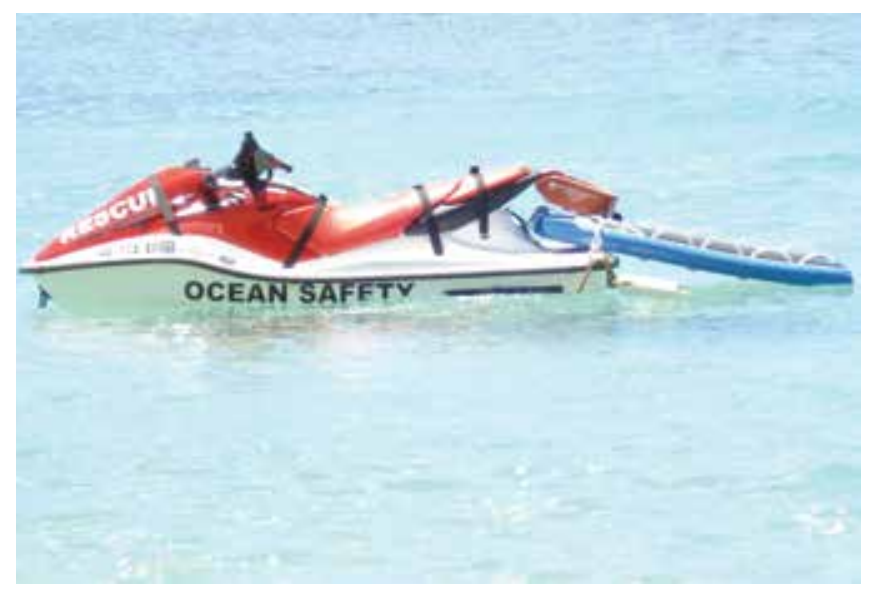

Figure 2. Jet-ski and Rescue sled Credit: Andrew Nathanson.

\section{Future directions}

Artificial wave pools and foiling surfboards are novel developments shaping the future of surfing. Uniform waves at predictable intervals in close proximity to land can be produced at wave pools, which provide a safe environment for those rehabilitating from injury, those learning to surf, and for competitions. In a wave pool the size and shape of the wave can be controlled, the bottom is uniform, there are no hazardous marine animals, and lifeguards and instructors can be close at hand.

Foiling is revolutionizing watersports such as sailing, kiting and surfing. Underwater, airplane shaped foils create lift at relatively low speeds and allow surfer and board to glide above the water's surface, minimizing water resistance. Foiling allows for long, smooth, fast rides in bumpy, mushy, on-shore conditions that would otherwise be considered mediocre for surfing. Skilled surfers can even pump themselves seaward, eliminating the need to paddle out, or glide down open-ocean swells on a SUP. However, the large, multi-tipped foil is capable of inflicting severe lacerations to its rider and others. Therefore, participants should wear a helmet, use a long leash and should consider wearing an impact vest. Surf-foiling is safest in un-crowded, crumbling waves breaking in deeper water. Foils should be designed with rounded wing-tips and dull trailing edges to minimize risk of lacerations and penetrating trauma.

\section{CONCLUSIONS}

Surfing appears to be relatively safe when compared to other extreme sports. Risk of injury is increased when surfing in larger waves, over a hard (as compared to sandy) bottom, and with advancing age. Most injuries occur when a surfer

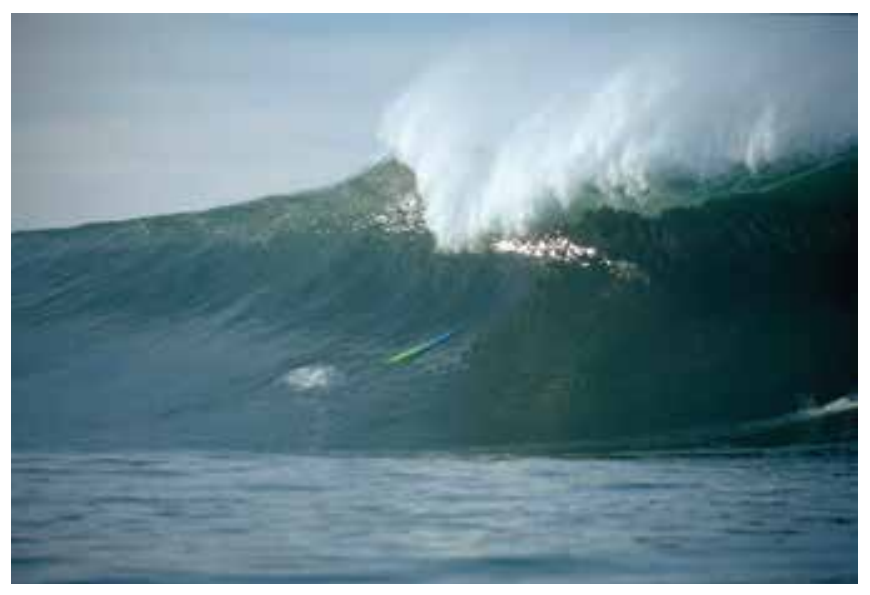

Figure 3. Surfer has abandoned board and is swimming through base of wave at Maverick's. Credit: Doug Acton.

Muscles, Ligaments and Tendons Journal 2020;10 (2) 
collides with his/her own board, with the sea floor, or from the hydraulic force of a breaking wave. Catastrophic and fatal injuries are uncommon, but include head and cervical spine injuries, as well as drowning. Risks of injury can likely be mitigated by slight modifications to the surfboard, as well as use of person-protective gear. In very large surf, floatation personal devices and coordination with a jet-ski driver are recommended. Man-made wave pools may provide a safe

\section{REFERENCES}

1. Warshaw M. The history of surfing. San Francisco: Chronicle Books; 2010, p. 22.

2. WSL World Tour History https://www.worldsurfleague.com/ pages/history Accessed 10 Aug 2019.

3. Campos F, Portugal A, Melo R in Sports "Tourism: New Challenges in a Globalized World" editors Melo R, Sorbet C. London: Cambridge Scholars Publishing; 2017. p 285-86.

4. Lowdon B, Pateman N, Pitman A. Surfboard-riding Injuries. Med J Aust. 1983;2:613-6.

5. Lowdon B, Pateman N, Pitman A, Kenneth R. Injuries to international competitive surfboard riders. J Sports Med. 1987;27:57-63.

6. Furness J, Hing W, Walsh J, Abbott A, Sheppard JM, Climstein $M$. Acute injuries in recreational and competitive surfers: incidence, severity, location, type, and mechanism. Am J Sports Med. 2015 May;43(5):1246-54.

7. Nathanson A, Bird S, Dao L, Tam-Sing K. Competitive surfing injuries: a prospective study of surfing related injuries among contest surfers. Am J Sports Med. 2007;35(1):113-7.

8. Nathanson A, Haynes P, Galanis D. Surfing injuries. Am J Emerg Med. 2002;20:155-60.

9. Klick C, Jones CM, Adler D. Surfing USA: an epidemiological study of surfing injuries presenting to US EDs 2002 to 2013. Am J Emerg Med. 2016 Aug;34(8):1491-6.

10. Taylor D, Bennett D, Carter M, Garewal D, Finch C. Acute injury and chronic disability resulting from surfboard riding. J Sci Med Sport. 2004;7(4):429-37.

11. Hay C, Barton S, Sulkin T. Recreational surfing injuries in Cornwall, United Kingdom. Wilderness Environ Med. 2009;20:335-8.

12. Chang L, McDanal C. Boardsurfing and bodysurfing injuries requiring hospitalization in Honolulu. Hawaii Med. 1980;39:117.

13. Jubbal KT, Chen C, Costantini T, Herrera F, Dobke M, Suliman A. Analysis of Surfing Injuries Presenting in the Acute Trauma Setting. Ann Plast Surg. 2017 May;78(5 Suppl 4):233237.

14. Hohn E, Robinson S, Merriman J, Parrish R, Kramer W. Orthopedic Injuries in Professional Surfers: A Retrospective Study at a Single Orthopedic Center. Clin J Sports Med. 2018;0:1-5.

15. Farrell Terrance, DO Big Wave Surfing: A Physician's Perspective. http://journal.surfersmedicalassociation.org/big-wave-surfing-a-physicians-perspective/ accessed: May 10, 2019.

16. Wong B, Cervantes W, Doyle K, Karamzadeh A, Boys P, Brauel G, Mushtaq E. Prevalence of external auditory canal exostoses in surfers. Arch Otolaryngol Head Neck Surg. 1999; 125:969-72. environment for training, those rehabilitating from injury, and surfing competitions. The adoption of surf foiling presents a new set of risks to the surfer and others from the large, sharp underwater foil.

\section{CONFLICT OF INTERESTS}

The authors declare that they have no conflict of interests (38).
17. International Shark attack files trends. Accessed: April, 2019. https://www.floridamuseum.ufl.edu/shark-attacks/trends/ fatalities/

18. Wu R. Case Report: A 29-Year-Old Female Surfer with a Thigh Laceration. Surfing Medicine Issue \#29 August, 2016 Accessed: July 16, 2019 http://journal.surfersmedicalassociation.org/case-report-a-29-year-old-female-surfer-with-a-thighlaceration/

19. Lopez G. In Nathanson, A, Everline C, Rennerker M., editors. Surf Survival: the surfer's health handbook 2nd ed. New York: Skyhorse Publishing; 2019 p. xi Forward.

20. Chang S, Tominaga G, Wong J, Weldon E, Kaan K. Risk factors for water sports-related cervical spine injuries. J Trauma. 2006;60:1041-6.

21. Cheng CL, Wolf L, Mirvis S, Robinson L. Bodysurfing accidents resulting in cervical spine injuries. Spine. 1992; 17:257-60.

22. Thompson T, Pearce J, et al. Surfer's myelopathy. Spine. 2004;29:353-6.

23. Choi JH, Ha JK, Kim CH, Park JH. Surfer's Myelopathy: Case Series and Literature Review. J Korean Neurosurg Soc. 2018 Nov;61:767-773.

24. Kim J, McDonald H, Rubsamen P, Luttrall J, Drouilhet J, Frambach D, et al . Surfing-related ocular injuries. Retina. 1998;18(5):424-9.

25. Galanis, D Accesses: September 3, 2019. https://health.hawaii. gov/injuryprevention/files/2015/08/wsocon15a.pdf

26. Gartside L. How dangerous is surfing? Wavelength Accessed: June 17, 2019 https://wavelengthmag.com/how-dangerous-is-surfing/.

27. Nathanson A. In: Mei-Dan O, Carmont, M Editors Adventure and Extreme Sports Injuries, epidemiology, treatment, rehabilitation and prevention. London: Springer-Verlag; p. 149.

28. Renneker M. In: Nathanson, A, Everline C, Rennerker M., editors. Surf Survival: the surfer's health handbook $2^{\text {nd }} \mathrm{ed}$. New York: Skyhorse Publishing; 2019 p. 237.

29. List of people who died climbing Mount Everest. Accessed September 2, 2019. https://en.wikipedia.org/wiki/List_of_ people_who_died_climbing_Mount_Everest .

30. Jarvis $\bar{C}$. How has no one died at Jaws? Stab Accessed: June 8, 2019 https://stabmag.com/news/no-deaths-at-jaws-shanedorian-albee-layer/ .

31. Melekian B. Death Trip. The Surfer's Journal 2011;(20):34-6.

32. Nathanson A. In: Nathanson, A, Everline C, Rennerker M., editors. Surf Survival: the surfer's health handbook $2^{\text {nd }} \mathrm{ed}$. New York: Skyhorse Publishing; 2019 p.85-90. 
33. Howden J, Danks J, McCluskey P, Gillett M, Ghabrial R. Surfboard-related eye injuries in New South Wales: a 1-year prospective study. Med J Aust. 2014;201:532-4.

34. Taylor D, Bennett D, Carter M, Garewal D, Finch C. Perceptions of surfboard riders regarding the need for protective headgear. Wilderness Environ Med. 2005;16(2):75-80.

35. Dozier S, Wagner Jr RF, Black SA, Terracina J. Beachfront screening for skin cancer in Texas Gulf coast surfers. South Med J. 1997;90:55-8.
36. Burnett M, Wang S. Current sunscreen controversies: a critical review. Photodermatol Photoimmunol Photomed. 2011;27:58-67.

37. Fitz-Clarke JR. Breath-Hold Diving. Compr Physiol. 2018 Mar 25;8(2):585-630.

38. Padulo J, Oliva F, Frizziero A, Maffulli N. Muscles, Ligaments and Tendons Journal - Basic principles and recommendations in clinical and field Science Research: 2018 update. MLTJ 2018; 8(3): $305-307$. 